\title{
Toward Understanding Arab Women's Cultural Landscapes
}

\author{
Akram Shalghin \\ Department of English, Faculty of Arts and Languages, Jadara University, Jordan
}

Received: $16-02-2017$

Accepted: 29-03-2017

Published: 30-04-2017

doi:10.7575/aiac.ijclts.v.5n.2p.14

URL: http://dx.doi.org/10.7575/aiac.ijclts.v.5n.2p.14

\begin{abstract}
The cultural representation of women in the Arab world is a complex issue due to the sensitivity surrounding their status in the region. We are confronted with many ways in which women are misrepresented and distorted. There are false claims used by male dominated culture(s) in the Arab world about women and their intellectual and physical capabilities. Indeed, Arab women are often prevented from representing themselves. When they are present, they are conceptualized as serving a decorative purpose. When women are given platforms from which they may speak, they are expected to reiterate male discourses.The paper focuses on the cultural and political marginalization and misrepresentation of Arab women and describes a number of cultural biases against women in Arabic-speaking societies. Based on culturally constructed misconceptions, Arab women are effaced and excluded from decision-making processes both politically, where they are subjugated and denied a social voice in the public sphere in favour of maledominated discourses, and within the private sphere of the family where they are subordinate to male relatives.
\end{abstract}

Keywords: Arab Women, Cultural Exclusion, Male Domination, Female Internalization of Male Discourses

\section{Introduction}

The photograph below was taken at a conference on "Women and Society", which was held in Saudi Arabia at Al Qasseem University on 10 April 2012. Though the conference was focused on social position of women, there were no women present, neither as contributors nor as attendees.i I suggest the spectre of this woman-less conference on women may be seen as a metaphor for the ways women in male-dominated Arab society are generally considered to be unable, as Karl Marx so succinctly put it, to "represent themselves. [Instead, women] must be represented." $i i$

The field of men, in this image, all of whom look the same, powerfully effaces the complexity of women's lived experience, as if women were being hidden behind a wall of men's bland, texture-less assertions and banal representations of protection, honour, lack of capacity and intellectual inadequacy. We can view this photograph as a complex metaphor; indeed, we can view it as a two-dimensional representation of the absence of an absence, as opposed to the presence of an absence.

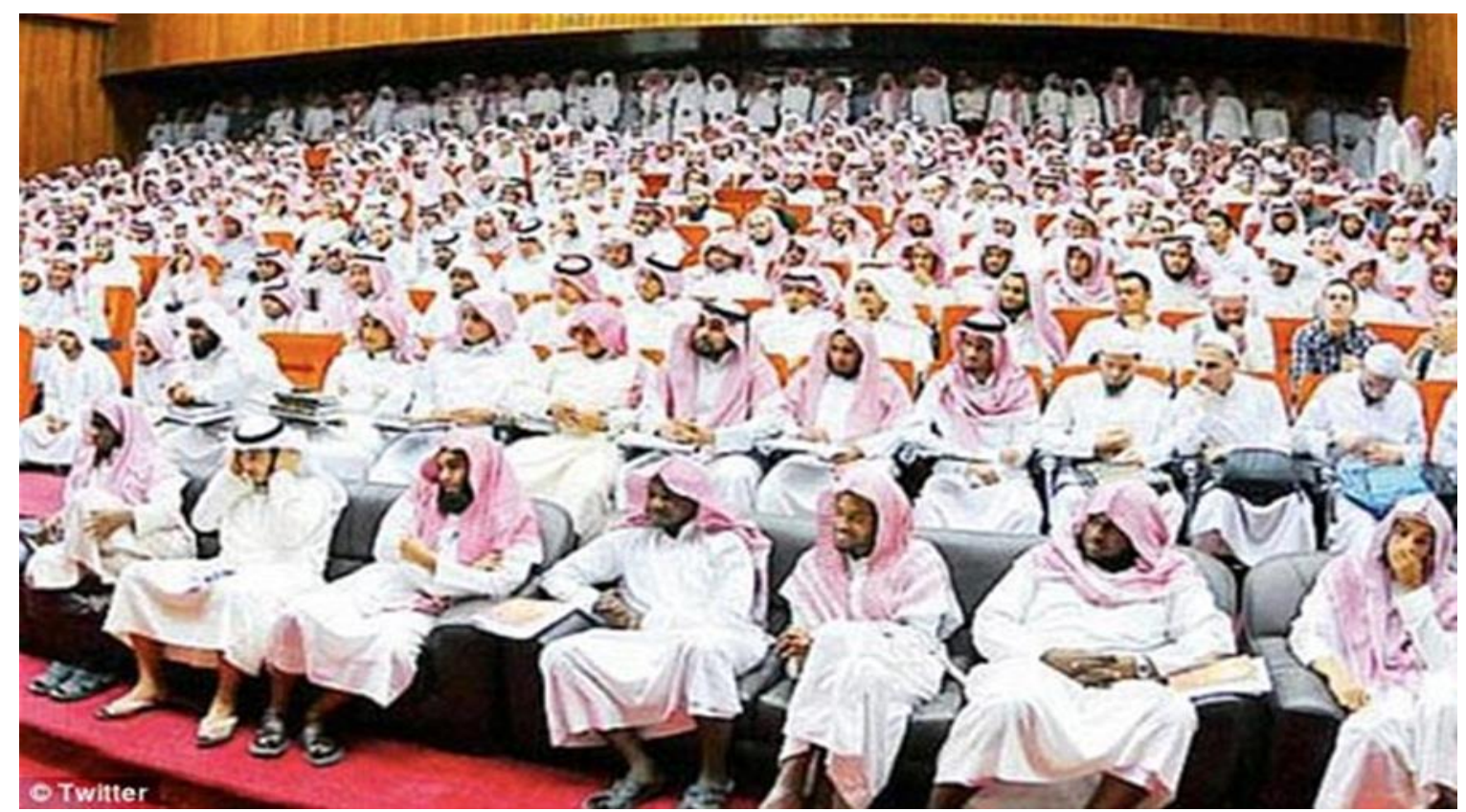

I would go even farther than Karl Marx' statement on representation above, however, to call attention to the ways women are systematically prevented even from attempting self-representation. Not only are they constructed as deficient, unable to engage in category-construction and meaning-making related to genderiii but women are also effaced through a forced physical, social, and religious sequestration and silencing. 
Our knowledge of the cultural spheres in which women are still struggling to obtain the right to be able legally to drive a car would leave us in no doubts that the absence of women is a deliberate bias against them. By no means, the absence of women could be taken to mean representation and giving a platform from which the voice of the social and cultural critique by women can be heard. The male omnipresence in contrast to total female absence made this conference on women a scandalously "womanless conference" on women.

My choice to start an exploration of the representation of women in the Arab world with this photo is motivated by two objectives. First, I seek to show how the University, which is constructed as the highest level of academic institution, claims to represent women when it, and most certainly academics, efface women. Second, and no less significant than the first, I take this example from Saudi Arabia precisely because it is the country which most Arabs, and Muslims, regard as the centre of their world; it is simply the place where Mecca of the Arabs, and the Muslim world, is. In other words, Because Saudi Arabia is positioned as culturally central, positions taken in Saudi Arabia have an unusual social, political, and cultural power. Saudi Arabian institutional and legal attitudes, as a result, become the arbiters of what is regarded as appropriate treatment of women throughout the entire region. In fact, the systematic cultural exclusion of women in the Arab world is much more sophisticated and complex than simply physically and intellectually excluding them from an academic conference. These exclusions are manifested in multiple ways depending on the country itself and on the form and environment within which this systematic process is executed.

\section{Discussion}

In this paper, rather than delve into the specifics of a particular region or local cultural practices regarding women, I am interested in establishing, in broad strokes, several major ways in which women are subjugated as a first foray into elucidation of women's political and cultural marginalization. This is shown through bringing some cultural and linguistic examples on the way women are viewed and positioned. One of the concerns of this paper is, also, revealing the power politics through which the systematic process of marginalizing women is accomplished.

Women in the Arab world are viewed through the lens of their relationship to male protectors. There are, however, rare cases in which women are allowed to participate in public, life. This visible participation, however, is temporary, both initiated, permitted, and terminated at the whim of men. Moreover, participation in public realms is ultimately disadvantageous for women as I describe below. Further, I offer, here, an overview of the legal positioning of women, religious ideology as a cultural framework for locating women within specific spheres, and stereotypes of women's deficits and capacities to justify these legal positions and underpin familial practices of sequestration under the rubric of concepts of honour and respect. Thus, I seek to outline a series of topics or arenas related to women that require further development in order to appreciate local nuances.

It is important, at this stage, to remind ourselves that most societies and communities in the world have undergone through this active, politicized process of (distorted) representation and marginalization of women and marginalization of their roles throughout history. I hasten to make this qualification in order not to appear to single out Arab cultures and societies as the sole perpetrators of this dynamic with regards to the question of women and their roles in their respective societies. In fact, the history of the world has been marked by marginalizing, absenting, and exploiting women as Frederick Engels has shown us when exploring the grievances inflicted upon women since they accepted to play a role of convenience for men.iv

Despite the changes that took place in many parts of the world regarding women, contemporary Arab discourses, which we must view as male-controlled, show kind of radical resistances to substantial changes as far as women are concerned. These discourses use religious teachings, in particular, to justify a cultural bias against women. This bias is evident in the notion that "Men are the protectors and maintainers of women, because Allah has made one of them to exceed the other." $\mathrm{v}$ In this way, the subordinate role of women is constructed and justified legally as on behalf of women with the claim that there is a divine wisdom in marginalising them or situating them as subordinate to men. Indeed, many clerics endorse the idea that women are less capable than men; consequently, their spheres must be restricted to kitchen and household due to their limitation in educational and intellectual pursuits. For example, in the words of the salafist cleric named Abu Isshaq Alhwaini stated: "Learning is only for men [as] women remain ignorant no matter what they achieve." vi The majority of men would agree with this kind of view. They force women to stay at home under various pretexts. Ironically, some Arab men literally hide women under the pretext that this practice values and distinguishes them as "respectable women,"

In the Arab world, marriage is typically arranged on a woman's behalf through binding contracts negotiated by a woman's family in conjunction with the groom's. This negotiation on a woman's behalf, in contrast to her volitional choice of a partner, is conducted under many pretexts, most notably women's security, protection and fortification (creating a kind of sequestration for reasons defined locally in terms of honour and fencing). The overall procedures that should necessarily follow must be conducted by paying high dowries; thus marriage becomes a question of buying and selling instead of being a sanctified relationship between two individuals whose love towards each other should, supposedly, be genuine and much more valuable than the amount of money estimated in thousands that are written in a marriage contract. Even when a marriage is arranged women are officially excluded from the negotiation process. Wedding invitations are a powerful visual representation of this exclusion: only the names of male family members fathers of the bride and groom and the groom himself). These invitations often mention the name of the groom under the name of his father. For women, by contrast, her name is very often absent and replaced with a word (Kareematahu) that signifies the link to her father; it is likely that her name is replaced with one word indicating her existence in 
relation to a male (the daughter of $\mathrm{Mr} . \mathrm{Z}$ is the bride). This deliberate effacement marginalizes her independent identity. She is defined only through her dependency on her male relations.

\subsection{Women's Effacement within the Family}

Women's exclusions from public arenas in the Arab countries, I consider here, are evident in the ways men refuse to mention female relatives, that is their mothers, sisters, daughters, or wives. Few men would be willing to utter the word "mother" when asked about their origins and/or their parents. A typical Arab man is likely to speak of his family by saying: "my father comes from x town while my uncles, who are the mother's brothers, come from y town". In this way, women's origins and social positions are implied, but not stated explicitly. This kind of secrecy, caution, privacy, and circumscription, conceals the reality of women's lived experience. The kinds of investigation I am calling for would give us specific information about how women in specific regions of the Arab world are defined, associated, and attributed, including how their connection to male family members are conceptualized locally, linkages that pervade women's lives. Before marriage, a woman is the sister or the daughter of her brother or father respectively. After marriage, she is the wife of her husband, using his name. When she has children, she becomes the mother of her eldest male child. When Arab men are interrogated about this point, they frequently give perplexed answers that demonstrate, paradoxically, their interest in protecting women, ensuring their virtue, and the honor and social status of their male relatives.

The sense, amongst many contemporary Arab men, that these modes of control of women represent fairness and protection, when viewed in historical context, may appear persuasive. However, the situation of the Arab women today compared with that of women of other areas of the world, may be said to suggest that Arab women are abused and maltreated by global standards of human rights. There is a sharp contrast between how Arab women are depicted officially and particular women's' relationships to their local cultures and society. Regretfully, there is neither recognition nor acknowledgement from men that they ill-treat women with the justification that women are being protected, a dynamic exemplified in the sharp contrast between how laws in some Arab countries regard women and how cultural spheres locate and treat them. (Jordan as an example).vii

\subsection{Women's Equality: The Ambivalence of Patriotic Service}

I suggest men in the Arab world opportunistically exploit women. Due to patriotic or national liberation reasons, women have been mobilized for certain periods of time, as their efforts have been needed. When their participation has no longer been needed, they have been pushed again to the margin. This has been the case recently and throughout history. There are numberless examples of this dynamic in the Arab world. There is a famous from Algeria that is worth considering. For example, Jamila Bouhired is known for her role as a relentless freedom fighter against the French occupation of Algeria Jamila Bouhreid was shot and injured, imprisoned, and risked the death sentence. She was deported and later imprisoned in another country (France). But, what became of her, and other women like Zahra Bouzhreef (Zhareef), after the victory of the Algerians and their declaration of independence is something that can be described as a poor reward from a male dominated society. These women, unfortunately, had neither political nor social roles. They remained icons for intellectuals and freedom fighters in other places, but never in their own countries. Furthermore, we know from newspaper reports that Jamila Bouhreid has been struggling in recent years not only to survive poverty but also to get medical care. This kind of exploitation of women at certain times, and abuse of them at others, has occurred repeatedly in the history of the Arab women.

This dynamic of opportunistic exploitation of Arab women's patriotism is clear, as well, in the relationship of Palestinian men in relation to Palestinian women. A kind of double-dealing is evident in Arab men's' welcome, even encouragement, of the efforts of Palestinian women to take part in demonstrations against the Israeli occupation. However, men turn against the idea of women engaging to the point of taking on public roles. Men's refusal to have familial ties with women who have taken on public roles is justified with an excuse based on activist women's compromised health, which would cause problems during a pregnancy and childbirth, as politically engaged women may have been "subject to tear gas bombs." In this way, men disavow any sort of commitment or obligation to the women they previously needed to resist Israeli occupation. For a neutral observer, the obvious reason for this attribution of compromised fertility has to do with the public political participation of the woman in question. To the men around her, she is classified as subversive/ she has overreached her role and has exceeded the acceptable limitations of a woman who may be considered future spouse. The Palestinian woman writer, Sahar Khalifeh, in her 1984 novel Abbad Al Shams (The Sunflower), describes similar behavior when she writes about the sophisticated, and contradictory, relationship between an educated man, named Adel, a leftist who is originally a son of a feudalist, and a female journalist, in her thirties, named Rafeef. Abdel admires Rafeef and desires her, but would never allow himself to fall in love with her, nor consider marrying her. He sees her as "an Arab girl who wants love, something he is not capable of'! viii It seems, he loves her but he is not capable of being with her eventually because of her being a journalist rather than being politically a disengaged woman.

Arab men's discourse of being, physically and mentally, the fittest is used to enhance the perception of what role should be allotted to women. This discourse of fitness hinders women's efforts to find appropriate employment with concomitant compensation. In fact, and this remains currently a wishful thinking, life would be easier and women would get better representation if they were able to live fully independently without any social, cultural and economic restrictions. The limitations currently place on women by men are clear efforts to place women at the margin instead of allowing them to enjoy full social rights and a place at the centre of the socio-political arena. Currently, most men 
would claim that they make money therefore, it is appropriate that they set the rules. Men would, in turn, see things in their real shapes without any hegemony or control over the social and cultural horizons of women.

\subsection{Women's Internalization of Masculinist Discourse}

One effect of men's marginalization of women is that Arab women themselves have internalized masculinist discourse and ideology. Thus, we see Arab women, themselves, using masculine language to express themselves linguistically and culturally. An example of this dynamic is the way in which women frequently express themselves using grammatical forms and vocabulary normally used by men. Linguistically, women have gender-specific ways to express themselves in a feminine mode. Despite this availability of gendered linguistic forms, women will frequently say 'I am sorry' in the same way a man would express it (ana assef instead of ana assefah)! This is not a unique example. Rather it is everywhere where the cultural horizon overcomes the linguistic to the extent that women internalize bias against themselves.

The internalization of male forms and ideas is more dangerous when it extends to cultural dimensions and is taken to its extreme; an outrageous example of this phenomenon comes from a poetry reading held on the $25^{\text {th }}$ April 2014 at the historic site of Umm Qais (or Gadara). A female poet was introduced as representing a feminist voice. The poem she read dealt with the story of a woman whose husband married a second woman.ix The so-called "feminist" poetess was blaming what happened on the first wife's inadequacy: she was not sufficiently seductive in relation to her husband/ The subject's inability to keep her husband fully satisfied caused him to look for warmth outside of the home. The poet, implicitly, blamed the wife for her husband's involvement with other women..! In this way, the poet blamed the husband's betrayal of his wife, not on the husband and his lust, but rather on the wife for not performing a satisfactory role and being sexy enough for her lascivious husband.x The poet's exposition of this idea was received with enthusiastic applause by both the men and the women listening to her. The poet resumed explaining that it is quite normal for a man to get married to two, three or four wives, as this is allowed by religion, in this way also finding religious legitimation (legitimization) for the practice.

The masculine-centric perspective articulated within the poetry described above, is ideologically similar to a vote that took place in March 2015. Algerian women in parliament voted against their own interests when they sided with conservative ideas and voted against laws that would guarantee fair treatment of women. Specifically, female parliamentarians voted against new laws that would give women better representation and fair social treatment. Female parliamentarians claimed that women cannot be entrusted in the manner required by the proposed legislation and, like their male counterparts, used religious discourse as a justification for their positions within parliament. However, women's support of conservative politics would not give us a glimpse into the fact that women are participating in this society. Rather, their participation is obliterated by the obvious way wherein women internalize male dogmatic discourses. Thus a question should be raised about what are women really doing when they cast votes against themselves, claiming that women are not capable of managing themselves?

When talking about Arab women and their image one cannot but draw a reference to the Arab women amidst what is called the "Arab Spring." Regretfully, this turned to be no season whatsoever for Arab women who were later subject to storms of suffering, further marginalization and exploitation. Who would forget how warring factions in Syria used women in the Arab Spring for sexual relief? Who can ignore that a girl was stoned to death in Al-Raqqah (Syria) for having a page on the social media platform, Facebook? The political events of recent years brought Arab women to a point where they suffer from all kinds of exploitation, paradoxically, conducted under the pretext of protecting them. In particular, young girls (Syrian) are sold to elderly Arab men for the price of two or three thousand US Dollars for the duration of a couple of months, at which point the girls are abandoned and replaced by younger girls.xi

\section{Conclusion}

The above cultural map has to do with men and their values. None of these representations, necessarily, gets at what women are wanting, doing, thinking, and talking about. This is a brief description of the mis-representation, absence and the distorted images of women in the Arab world. Listing Arab women's grievances would show a much more horrible picture than what I have represented here. Arab women should not have to live in the roles currently available to them, so long as those societies distort women's image. Rather women must struggle to reshape Arabic culture(s) perceptions of women.

\section{References}

Abo Ayash, B. (2014). Poems Recited in Umm Qais, North of Jordan.

Engels, F. (1942). "The Origin of the Family, Private Property and the State" in particular, the part on "The Family" in Works of Fredrick Engels 1884 in Marx/Engels Selected Works, Volume Three tans. into English by Alick West. Hottingen-Zurich.

Khalifeh, S. (1984). Abbad Al Shams, $3^{\text {rd }}$ ed. Damascus, Dar AlJaleel.

Marx, K. (1937). The 18th Brumaire of Louise Bonaparte (1852). Translated and published. Moscow: Progress Publishers.

McConnell-Ginet, S. (2014). Meaning-making and ideologies of gender and sexuality in S. Ehrlich, M. Meyerhoff, \& J. Holmes (eds.), The Handbook of Language, Gender, and Sexuality, 2nd edition (pp. 316-334). Oxford: Wiley Blackwell 
Qur'an, "Surah al Nisa" verse 34

https://www.youtube.com/watch?v=s1bS4gitoS0

TV documentaries and UN reports on the issue. See, for example, http://thecreatorsproject.vice.com/blog/virtual-realitydoc-puts-you-inside-a-syrian-refugee-camp

\section{Notes}

i It has been a successful attempt of mine, so far, to evade writing about "Arab women's image and/or their representation." This escape has never been related to giving precedence to other questions over that of women, nor has it been due to the wrong assumption that women's issues can be properly understood, and thus spoken of, solely by women themselves. Rather, the previous reluctance to get into this topic has been ultimately due to my concern not to oversimplify such a vital and critical topic. Indeed, women's image(s) and/or their representation in the Arab world righteously deserve attention, review, research, examination and work much more than what the limitations of this brief paper allow. This is not to mention the unintentional oversimplification of the socio-political dimensions of the issue and the cultural roots related to it, factors that will inevitably place the matter at the centre of controversy. See image 1.

ii Karl Marx, The $18^{\text {th }}$ Brumaire of Louise Bonaparte (1852). Translated and published (Moscow: Progress Publishers, 1937), P. 62.

iii See McConnell-Ginet, S. (2014). "Meaning-Making and Ideologies of Gender and Sexuality" in S. Ehrlich, M. Meyerhoff, \& J. Holmes (eds.), The handbook of Language, Gender, and Sexuality, 2nd edition (pp. 316-334). Oxford: Wiley Blackwell.

iv It is not unneeded to bring here the question of women and the theory of the family laid out by Frederick Engels regarding the historical mistake that was committed against women, and the historical mistake by women themselves when accepting the roles allotted to them. According to Engels, the historical displacement of women from power within society occurs with the rise to prominence of social functions associated with men. With the change from matrilineal inheritance to patrilineal inheritance, the significance of the female becomes primarily the production of male heirs. The form of the family becomes monogamy to ensure that the property of each male is inherited by his own children. In other words, sexuality is made a means for transforming property. In fact, woman herself becomes a piece of property carrying with her inherited wealth and a potential to unite families through common descent. Since women are treated as private property, the form of their exploitation, according to Marx, will mirror the dominant property form. Thus, the change in the form of property from feudalism to capitalism affects the nature of social control exercised over women. Feudal property admitted multiple ownership, everyone from the king to the surf would have some rights over a single piece of land. No decision concerning the land could be made without the consent of one's immediate feudal overlord. Similarly, no woman could be given in marriage without the lord's consent. Capitalist property, on the other hand, bestows complete power over the property to the individual owner. Thus marriage contracts could be negotiated directly and were less subject to social control. See Frederick Engels, "The Origin of the Family, Private Property and the State" in particular, the part on "The Family" in Works of Fredrick Engels 1884 in Marx/Engels Selected Works, Volume Three tans. into English by Alick West (Hottingen-Zurich: 1942).

v See "Surah al Nisa" verse 34. men are the maintainers of women for that Allah has preferred in bounty one of them over another, and for that they have spent of their wealth

vi See, https://www.youtube.com/watch?v=s1bS4gitoS0. My own translation.

vii In Jordan, there is a clear incompatibility when it comes to the jurisdictional rights of women and the actual cultural latitudes within which they are confined!

viii Sahar Khalifeh, Abbad Al Shams, $3^{\text {rd }}$ ed. (Damascus, Dar AlJaleel: 1984), p.16.

ix To have more than one wife is legally allowed in the Arab world, it is compatible with religious teachings.

$x$ It was the poem recited by the female poet Basma Abo Ayash in Umm Qais, North of Jordan on April $25^{\text {th }} 2014$.

xiSee TV documentaries and UN reports on the issue. See, for example, http://thecreatorsproject.vice.com/blog/virtualreality-doc-puts-you-inside-a-syrian-refugee-camp,http://www.aljazeera.com/indepth/features/2013/11/teenage-syrianrefugees-wed-protection-201311101497543146.html. 